\title{
Analysis of Mixture of Maltooligoses Using MALDI-TOFMS: Influence of Cationizing Agent Types
}

\author{
Sung-Seen Choi and Hye Min Lee

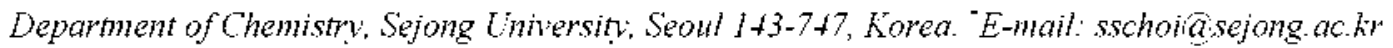 \\ Received September 4, 2009. Accepted September 23, 2009
}

Key Words: MALDI. Maltooligoses. Size effect. Alkali metal salt. Cation adduction

Carbohydrates are the most abundant and structurally diverse compounds found in nature and serve the dual purpose of being stnictural components and key players of the energy metabolism. ${ }^{3}$ Carbohydrates. either alone or as constituents of glycoproteins proteoglycans and glycolipids. are mediators of cellular events such as intra- and extracellular recognition. differentiation. proliferation, and even signal transduction. teins and micleic acids. which are linear poly mers of amino acids and nucleotides respectively. carbolydrates can adopt complex branched stnictures with individual monomeric units linked at one of several sites. ${ }^{8}$ Mass spectrometry is an important tool for the structural analy sis of carbohydrates. and offers precise results. analytical versatility, and very high sensitivity ${ }^{9}$ Soft ionization techniques such as matrix-assisted laser desorption and ionization (MALDI) and atmospheric pressure ionization (API) have been used for linkage and sequence determination of oligosaccharides. ${ }^{1+\llcorner\hat{\imath}}$ In MALDI. carbolyydrates most often ionize by adduction of metal ions in contrast to the more usual $\left[\mathrm{M}+\mathrm{H}^{+}\right.$ion produced by proteins. ${ }^{1(1-1), \geq 5}$ MALDI has been found to be from 10 to 100 times more sensitive than fast atom bombardment $(\mathrm{FAB})$ or plasma desorption (PD) mass spectrometry for carbohydrate and gly coprotein analy sis. ${ }^{26-25}$ Several researches ${ }^{12.31 .34}$ reported that the ion abundances of carbohy drates were varied in accordance with the molecular size. In the present work, we analyzed maltooligosaccharides using MALDI and the sample was prepared with a cationizing agent to enlance the ionization efficiency. Nine alkali metal salts were employed as the cationizing agents and the differences in the ionization efficiencies depending on the cationizing agents. were compared.

We prepared the sample by mixing 1 aliquot of the $5 \mathrm{mM}$ carbolydrate mixture solution with 5 aliquots of the $100 \mathrm{mM}$ matrix solution, which yields an analyte to matrix ratio of $1: 100$. Concentrations of the alkali metal salts were $1 \mathrm{mM}$. Figure 1 shows MALDI-TOF mass spectra of the samples containing LiTFA. NaTFA and KTFA as the cationizing agent. respectively. The $[\mathrm{M}+\text { cation] }]^{-}$ions of the alkali metal cations were clearly observed in the mass spectra but the protonated molecules. $[\mathrm{M}+\mathrm{H}]^{-}$were not detected. The cation-adducted ions of maltotriose (DP3). maltotetraose (DP4). maltopentaose (DP5). maltohexaose (DP6), and maltoheptaose (DP7) were detected. but those of glucose (DP1) and maltose (DP2) were not observed. The relative intensity of the $[\mathrm{M}+\text { cation }]^{+}$increases as the maltooligose size increases. The reason for no detection of the $[\mathrm{M}+\text { cation }]^{-}$ions of DPl and DP2 may be due to the matrix su- ppression. Bashir and coworkers ${ }^{35}$ studied MALDI analysis of glucose and reported that $[\mathrm{M}+\mathrm{Na}]^{-}$of glucose was produced at high analyte concentration. The increasing cationization efficiency of large maltooligose can be explained with the nultidentate coordination. Cerda and Wesdemiotis ${ }^{36}$ suggested that for $\mathrm{Na}^{-}$coordinated saccharides the $\mathrm{Na}^{-}$affinity was consistent with the saccharides being multidentate ligands to $\mathrm{Na}^{+}$. Lee and coworkers ${ }^{35}$ reported that $\mathrm{Na}^{+}$coordinated with all four sugar moieties of maltotetraose. Thus, the peak intensity of [M+cation] will enhance as the sample size increases since the number of coordination sites increases.

For the sample containing lithium cation, the product ions. besides the $[\mathrm{M}+\mathrm{Li}]^{+}$ions of maltooligoses (DP3 - DP7), the $[\mathrm{M}+\mathrm{Na}]^{+}$and $[\mathrm{M}+\mathrm{K}]^{-}$ions were also observed. The sodium and potassium cations may come from the sugars or glassware

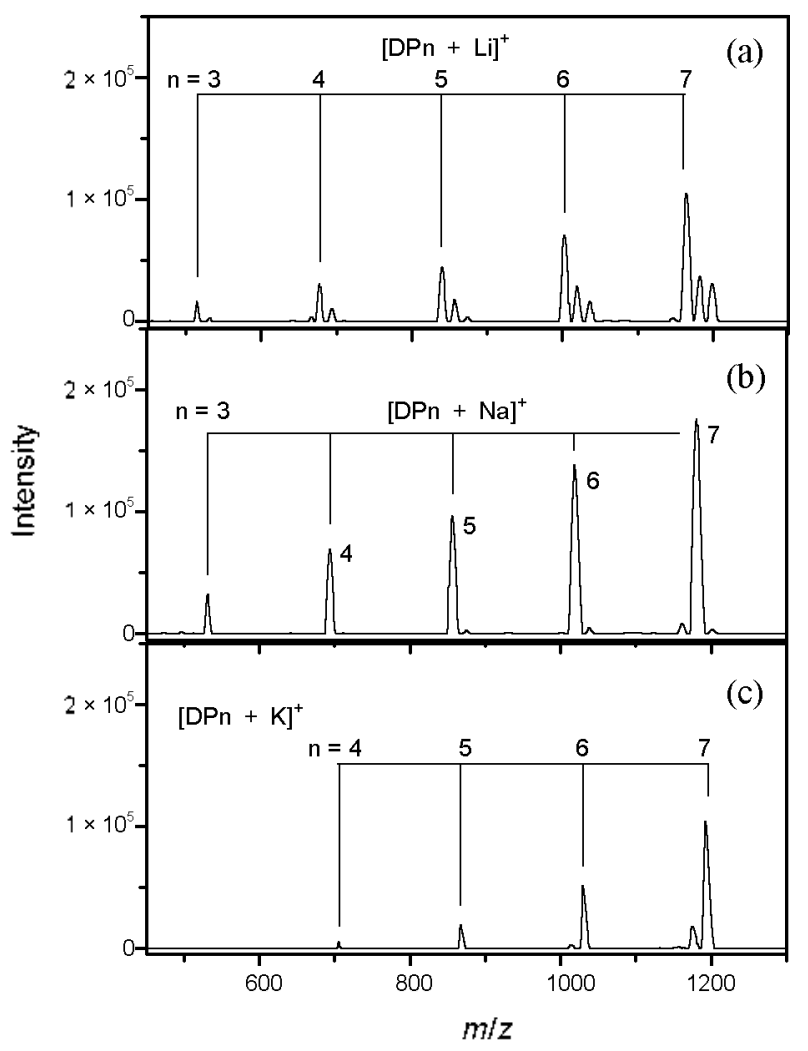

Figure 1. MALDI-TOF mass spectra of misture of glucose and maltooligoses containing LiTFA (a), NaTFA (b), and KTFA (c) as a cationizing agent. 


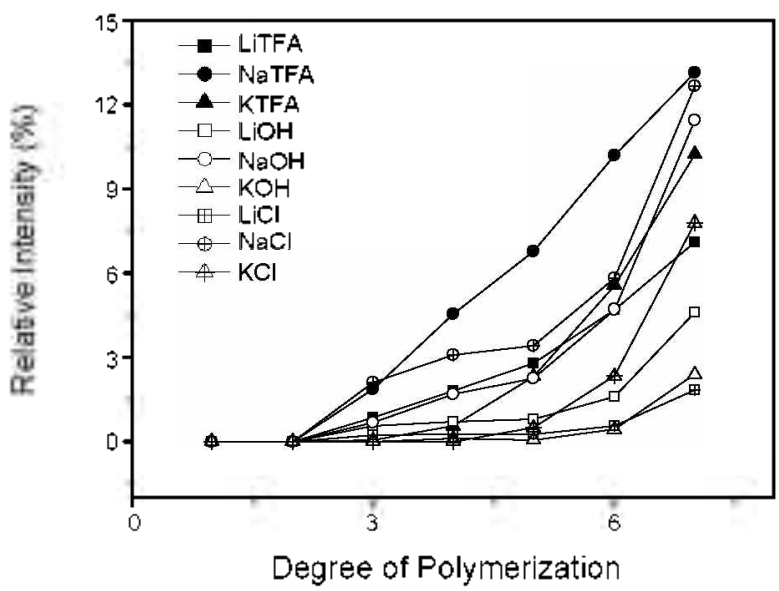

Figure 2. Variation of the relative intensities of $\left[\mathrm{M}+\right.$ cation $^{+}$with the degree of polymerization of saccharides. The peak intensities were nommalized with $\left[\mathrm{DHB}+\mathrm{H}-\mathrm{H}_{2} \mathrm{O}\right]^{-}$. Squares, circles, and triangles, and down-triangles stand for the $[\mathrm{M}+\mathrm{Li}]^{+},[\mathrm{M}+\mathrm{Na}]^{-}$, and $[\mathrm{M}+\mathrm{K}]^{+}$, respectively. Solid, open, and crossed symbols indicate the CatTHA, $\mathrm{CatOH}$, and $\mathrm{CatCl}$, respectively

because MALDI mass spectra of oligosaccharides without any cationizing agents displayed only $\left[\mathrm{M}+\mathrm{Na}^{+}\right.$and $[\mathrm{M}+\mathrm{K}]^{-}$ions. ${ }^{38}$ Formation of the abundant $[\mathrm{M}+\mathrm{Na}]^{+}$and $[\mathrm{M}+\mathrm{K}]^{-}$ions in the sample containing lithium cation means that the adduction capability of $\mathrm{Li}^{-}$to the oligosaccharides is relatively much lower than those of $\mathrm{Na}^{-}$and $\mathrm{K}^{+}$. The mass spectrum of the sample containing sodium cation displays the ion distributions of $[\mathrm{M}+\mathrm{Na}]^{-}$from DP3 to DP7. Of the mass spectra of $\mathrm{Li}^{+}$. $\mathrm{Na}^{-}$, and $\mathrm{K}^{-}$, the peak intensities of $[\mathrm{M}+\text { cation }]^{-}$ions of $\mathrm{Na}^{-}$are larger than the others. Dehydrated products of [DP6 $\left.+\mathrm{Na}-\mathrm{H}_{3} \mathrm{O}\right]^{-}$and $[\mathrm{DP} 7+\mathrm{Na}-$ $\left.\mathrm{H}_{2} \mathrm{O}\right]^{+}$ions formed from the $[\mathrm{DP} 6+\mathrm{Na}]^{+}$and $[\mathrm{DP} 7+\mathrm{Na}]^{+}$ ions were observed. The $\left[\mathrm{DP} 6+\mathrm{Na}^{-} \mathrm{H}_{2} \mathrm{O}\right]^{+}$and $[\mathrm{DP} 7+\mathrm{Na}-$ $\mathrm{H}_{2} \mathrm{O}^{-}$ions were particularly observed in the mass spectrum of the sodium cation. In the previous work. ${ }^{12}$ we reported that the two terninal monomers of the heptamer overlapped and the delydration reaction could occur between two hydroxyl groups of the both terminal monomers. The mass spectrum of the sample containing potassium cation displays the ion distributions of $[\mathrm{M}+\mathrm{K}]^{+}$ions and the $[\mathrm{DP} 6+\mathrm{Na}]^{-}$and $[\mathrm{DP} 7+\mathrm{Na}]^{-}$ions are also observed. The $[\mathrm{DP} 3+\mathrm{K}]^{-}$ion was detected by trace.

We investigated not only the alkali metal types but also the counter anion types on the ionization efficiencies of maltooligosaccharides using CatTFA. $\mathrm{CatOH}$, and $\mathrm{CatCl}$. The relative intensity of [M + cation $]^{-}$was compared in terms of the cation and anion types as well as the analyte size. The relative intensity of $[\mathrm{M}+\text { cation }]^{-}$was nonmalized with $\left[\mathrm{DHB}+\mathrm{H}-\mathrm{H}_{-} \mathrm{O}\right]^{+}$because the $\left[\mathrm{DHB}+\mathrm{H}-\mathrm{H}_{2} \mathrm{O}\right]^{+}$is the most abundant product ion. The relative intensity of $[\mathrm{M}+\text { cation }]^{+}$varies with the cation and anion types as well as the analy te size as shown in Figure 2. All the relative intensities of $[\mathrm{M}+\text { cation] }]^{-}$increase with increasing the sugar size irrespective of kinds of cations and anions. Likewise the relative intensities of $[\mathrm{M}+\mathrm{Na}]^{+}$are much larger than those of the $[\mathrm{M}+\mathrm{Li}]^{-}$and $[\mathrm{M}+\mathrm{K}]^{+}$ions irrespective of the kind of anions. In ESI-MS, the ion distributions of $[\mathrm{M}+\text { cation }]^{-}$ showed a maximum peak at [DP2 + cation $]^{-}$, [DP3 + cation] ${ }^{-}$. or $[\mathrm{DP} 4+\text { cation }]^{-3 .}$.
The relative intensities of [M+ cation] ${ }^{-}$generated using CatTFA salts are larger than those using $\mathrm{CatOH}$ and $\mathrm{CatCl}$ salts. It is very interesting that the ionization efficiency of saccharide depends on the anion type of the salt as well as the cation type. It can be expected that anion of the salt affects state of the sample preparation, protonation to the matrix. and formation of cationmaltooligose complex. We first examined the crystalline state of the MALDI sample. but did not find something different. Next. we considered the anion behaviors in water solution Water solutions of $\mathrm{CatTFA}, \mathrm{CatOH}$. and $\mathrm{Cat} \mathrm{Cl}$ are weak alkaline. strong alkaline, and neutral. respectively. The salts are fully dissolved and some of the anions can be changed to their conjugate acids. Conjugate acids of TFA ${ }^{-} \mathrm{OH}^{-}$, and $\mathrm{Cl}^{-}$are $\mathrm{HTFA}, \mathrm{H}_{2} \mathrm{O}$. and $\mathrm{HCl}$. respectively. However only HTFA can be formed because $\mathrm{HCl}$ is strong acid and $\mathrm{H}_{2} \mathrm{O}$ is solvent. By the fonnation of HTFA. the metal cation of CatTFA can easily adduct to maltooligose.

The order of ion intensities of $[\mathrm{M}+\text { cation }]^{+}$with different cations shows some difference according to the anion type of salt. For CatTF A and $\mathrm{CatCl}$, the order of $[\mathrm{M}+\text { cation }]^{+}$intensity $\left(\mathrm{M}=\mathrm{DP} 6\right.$ and DP7) is $[\mathrm{M}+\mathrm{Na}]^{+}>[\mathrm{M}+\mathrm{K}]^{-}>[\mathrm{M}+\mathrm{Li}]^{-}$. For CatOH. the order is $[\mathrm{M}+\mathrm{Na}]^{+}>[\mathrm{M}+\mathrm{Li}]^{-}>[\mathrm{M}+\mathrm{K}]^{-}$. Our results were not consistent with binding affinities proposed by Molur and coworkers. ${ }^{39} \mathrm{Mohr}$ and coworkers analyzed maltoheptaose with high concentration $(0.25 \mathrm{M})$ of salt mixture and suggested that based on the relative abundance of alkali metal doped maltoheptaose. the order of binding affinities for carbohydrates was as follows: $\mathrm{Li}<\mathrm{Na}<\mathrm{K}$. This may be due to the state of alkali metal cation in the solid MALDI sample and the capacity to forn gas phase alkali metal cation by laser ablation. Ion intensity distributions of $[\mathrm{M}+\text { cation }]^{+}$using $\mathrm{Cat} \mathrm{Cl}$ vary with the maltooligose size as well as the cation type. The order of [DP7 + cation $]^{+}$intensity using $\mathrm{CatCl}$ is the same trend with the ion intensity order using CatTFA: $[\mathrm{DP} 7+\mathrm{Na}]^{+}>[\mathrm{DP} 7+$ $\mathrm{K}]^{-}>[\mathrm{DP} 7+\mathrm{Li}]^{-}$. From the experimental results. we found that CatTFA enhanced ionization efficiencies of maltooligoses more than $\mathrm{CatOH}$ and $\mathrm{CatCl}$. This was explained with the role of anion of the salt to improve the sample state. protonation to the matrix. and the formation of cation-maltooligose complex.

\section{Experimental Section}

Glucose, maltose maltotriose, maltotetraose, maltopentaose. maltohexaose. and maltoheptaose were purchased from Aldrich Co. (St. Louis, USA). 2.5-Dihy droxybenzoic acid (DHB) used as the matrix was also purchased from Aldrich Co. (St. Louis, USA). Lithium trifluoroacetate (LiTFA), sodium trifluoroacetate (NaTFA), potassium trifluoroacetate (KTFA). lithium hydroxide $(\mathrm{LiOH})$, sodium hydroxide $(\mathrm{NaOH})$. potassium hydroxide $(\mathrm{KOH})$. lithium chloride $(\mathrm{LiCl})$. sodium chloride $(\mathrm{NaCl})$. and potassium chloride $(\mathrm{KCl})$ were employed as the cationizing agents. and they were purchased from Aldrich $\mathrm{Co}$. (St. Louis. USA). The each saccharide ( $5 \mathrm{mM})$. matrix $(100 \mathrm{mM})$, and cationizing agent $(\mathrm{l} \mathrm{mM})$ were dissolved in deionized water. The seven saccharide solutions of glucose to maltoheptaose were mixed with the same concentration $(5 \mathrm{mM})$ and volume $(1 \mu \mathrm{L})$. The nixtrue of carbohydrates, matrix. and cationizing agent solutions were nuixed (nixture of carbolydrates : matrix : cationizing reagent $=1: 5: 1$ by volume ratio) . The mixed solution 
of $1 \mu \mathrm{L}$ was spotted onto the sample plate and was dried.

MALDI mass spectra were obtained with Axima-LNR MALDI-TOFMS (Kratos-Shimadzı Co. of Japan). Ions were produced by irradiation of the sample with nitrogen laser (337 num). Profiling of product ions was achieved in the positive mode using linear TOF. The accelerating voltage was $20 \mathrm{kV}$. The sum of 100 shots was collected for each spectnum.

\section{References}

1. Lamari, F. N.: Kulnn, R; Karananos, N. K. J. Chromatogr: $B$ $2003,793,15-36$.

2. Iozzo, R. V. Crit. Rev. Biochem. Aol. Biol. 1997, 32, 141-174

3. Bentield, M.: Gotte, M.: Park, P. W.: Reizes, O. Fitzgerald, M. L: Lincecunn. J.: Zako. M. Anmu. Rev. Biochem. 1999.68.729-778.

4. Schwartz, N. Fromt. Bioser. 2000, 5, D649-655.

5. Sugahara, K: Kitagawa, H. Cim Opin. Strict. Biol. 2000, 10, $518-527$.

6. Helenius, A.: Aebi. M. Science 2001, 291, 2364-2369.

7. Wells, L.: Vosseller, K. Hart, G. W. Scrence 2001, 291, 2376 2378 .

8. Harver, D. J. hth. J. A fass Spectrom. 2003, 226, 1-35

9. Zaia, T. Mass Spectrom. Rev. 2004, 23, 161-227.

10. Harvey, D. J. Mass Spectrom. Rev 1999,18, 349450.

11. Naven, T. I. P; Harvev, D. J. Rapid Conmnim. M Lass Spectrom 1996, $10.829-834$

12. Choi, S.-S.: Ha, S.-H. Bull Kor Chem Soc. 2006, 27, 1243-1245.

13. Harvey, D. I.; Küster, B.: Naven, T. T. P. Ghcoconingate J. 1998, $15,333-338$

14. Tseng, K.; Hedrick, T. L.; Lebrilla, C. B. Amal. Chem. 1999, 71, $3747-3754$

15. Price. N. P. J. Anal Chem. 2006, $78,5302-5308$

16. Viseux, N.: de Hiffmann, E.: Domon, B. Anal. Chem. 1998, 70, $4951-4959$

17. Weiskopt, A. S.: Vouros, P.; Harvey, D. T. Anat Chem. 1998, 70, $4441-4447$

18. Li, D. T.; Her, G. R. J. Mass Spectrom. 1998, 33, 644-652
19. Garozzo, D.: Impallomeni, G.: Spina, E.; Green, B. N.: Hutton, T. Cabohudr. Res. 1991, 221, 253-257.

20. Mulroney, B.; Traeger, T. C.: Stone, B. A. J. A Lass Spectrom. 1995. $30,1277-1283$

21. Yuan, J.; Hashii, N.; Kawasaki, N.: Itoh. S.: Kawanishi, T.: Hayakawa, T. J. Chomatogr A 2005, 1067, 145-152.

22. Wan. E. C. H.: Yu. J. Z. J. Chromatogr A 2006. 1107, 175-181.

23. Cheng, H. L.; Her, G. R. J. Am. Soc Mass Spectront. 2002, 13, $1322-1330$

24. Zhu, X.: Sato, T. Rapid Conmm Mass Spectrom. 2007, 21, 191198

25. Choi, S.-S.; Lee, H. M.; Jang, S.; Shin, J. Int. J. Mass Spectrom. 2009, 279,53-58

26. Huberty, M. C.: Vath, J. E:; Yu, W.: Martin, S. A. Anal Chem. 1993. 65.2791-2800

27. Garozzo, D.: Spina, E.; Sturiale, L.: Montaudo, G.: Rizzo, R. Rapid Commun. Hass Spectrom. 1994, 8, 358-360.

28. Shen, X.; Perreault, H. J. Chromatogr, A 1998, $811,47-59$

29. Tsarbopoulos, A.: Karas, M.; Strupat, K.: Pramanik, B. N.; Nagabhushan, T. L.; Hillenkamp, F. Anal Chem. 1994, 66 , 2062-2070

30. Kazmaier, T:- Roth, S.: Zapp, J:- Marding, M.; Kuhn, R. Fresenins J. Anal Chem 1998, 361, $473-478$

31. Wang, T., Tiang, G.; Vasanthan, T.; Spons, P. Starch 1999, 51, $243-248$

32. Lattova, E.; Perreault, H. J. Chrontatgr: B 2003, 793, 167-179.

33. Bashir, S.; Derrick, P. . .; Critchley, P.; Gates, P. . .; Staunton, J. Ew. J. Mass Spectrom. 2003, 9,61-70.

34. Choi, S.-S.: Kim, T-C. Bull Kor Chem Soc 2009, 30, 1996-2000.

35. Bashir, S.; Mutter, R.; Giannakopulos, A. E.; Wills, M.; Derrick, P. J. Anal. Chm. Acta 2004, 519, 181-187.

36. Cerda, B. A.: Wesdemiotis, C. Int. J. Mass Spectrom 1999, 189. 189-204.

37. Lee, S.; Wyttenbach, T:- Bowers, M. T. Int. J. Mass Spectront. Ion Processes 1997,167:168,605-614

38. Hao, C.; Ma, X.: Fang, S.; Liu, Z; Liu, S.; Song, F, Liu, J. Rapid. Commum. Mass Spectrom 1998, 12, 345-348

39. Mohr, M. D.: Bornsen, K. O.: Widmer, H. M. Rapid. Conmmin. Mass Spectrom. 1995, 9, 809-814. 